\title{
Experimental study on the performance analysis of river levee using new substance for improving earth surface resistance
}

\author{
Dongwoo $\mathrm{Ko}^{1}$, Joongu Kang ${ }^{1, *}$, Sungjoong $\mathrm{Kim}^{1}$ and Yonguk $\mathrm{Ryu}^{2}$ \\ ${ }^{1}$ Korea Institute of Civil Engineering and Building Technology \\ ${ }^{2}$ Pukyong National University
}

\begin{abstract}
The reasons why levee breaches during floods are largely due to overtopping, seepage, and structurally induced piping. According to an analysis of domestic and overseas reported cases of levee breaches, overtopping was found to be the cause for approximately $40 \%$ of all cases of breach. Despite such efforts of previous research to establish disaster prevention plans associated with levee breaches, to enhance our understanding of the processes and reasons, further research regarding the prediction of levee breaches must be undertaken by accumulating test data under several different conditions and further verification of the data using numerical models must also be undertaken. In this study, development of technologies regarding a new environmentally friendly bio-polymer capable of protecting levees from erosion is being undertaken. Breach mechanisms was assessed using an image measurement system that collected data regarding the breach progress of the levee, close-up views of the breaching surface, and the formation of the final breaching cross-sections. Further, levee slopes were covered with a bio-soil mixed with a new substance for the purpose of analyzing the stability and the time delay effect.
\end{abstract}

\section{Introduction}

River levees are structures that protect lowland areas from flood damage and are increasingly becoming important due to their role in preventing enormous degrees of property damage and human casualties caused by local torrential rainfalls linked with recent abnormal climate phenomena. Through hydraulic modelling tests, several domestic and overseas researchers have undertaken studies to analyse factors that affect levee breach such as the breach mechanism of levees of varying sizes, earth and sand densities, moisture content, compactness, and soil conditions $[1,2,3,4,5]$. However, a clear understanding of the reasons and mechanisms behind levee breaches is still considered to be unknown.

In this study, hydraulic experiments were carried out by building a mid-sized levee model in REC (Andong River Experiment Center) in Figure 1. By building a measuring system using image devices on site, failure mechanisms and processes were analysed during an overflow. In addition, levee slope was covered with a bio-soil for the purpose of analyzing

\footnotetext{
*Corresponding author : jgkang02@kict.re.kr
} 
the stability and performance of the levee applied with the new substance. Figure 2 shows view of hydraulic experiment in REC.

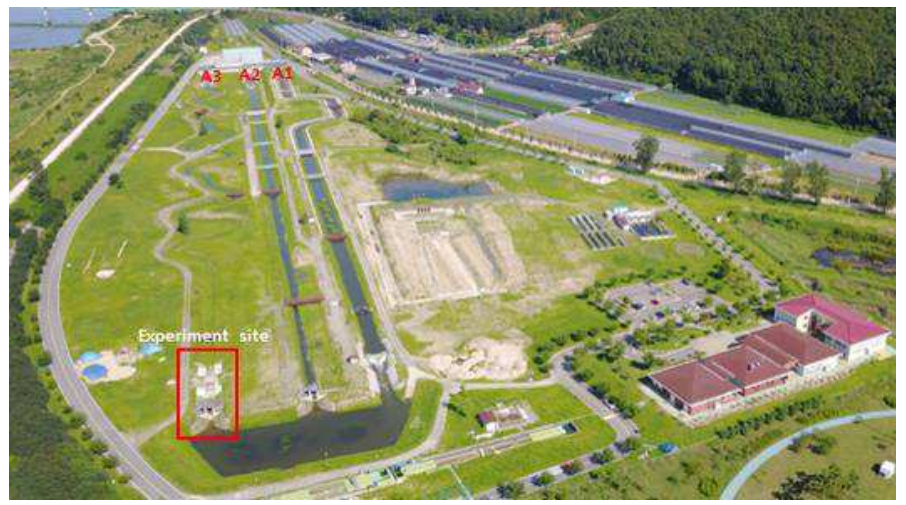

Fig. 1. View of REC in Andong, South Korea

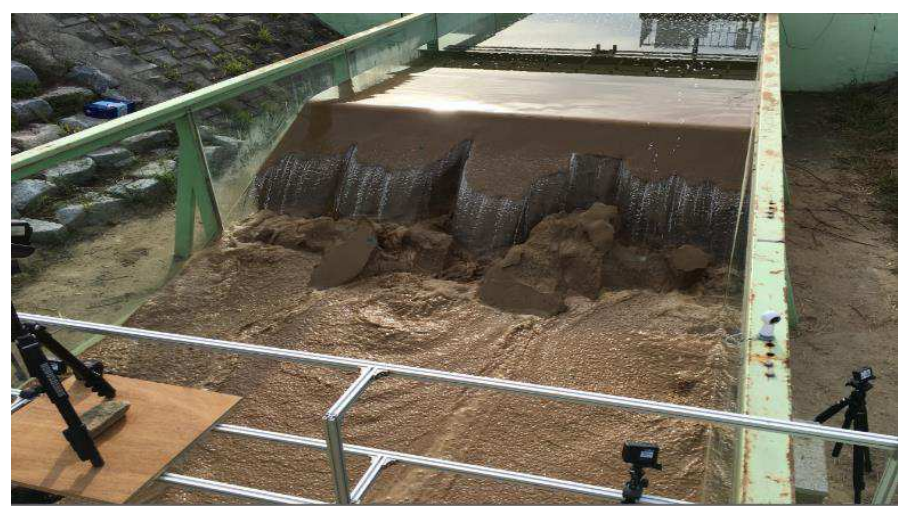

Fig. 2. Hydraulic experiment for levee failure by overtopping

\section{Experimental methods}

In terms of the characteristics of this levee experiment, a mid-sized levee was built with a total length of $5 \mathrm{~m}$, slope of $1: 2$, width of $3 \mathrm{~m}$, crown width of $1 \mathrm{~m}$, and a height of $1 \mathrm{~m}$ in the downstream area of a meandering channel (A3 channel) within the Andong River Experiment Center to minimize the effects of scaling that may occur during small scale hydraulic modeling experiments and to recreate the failure dynamics of levee bodies that occur due to overflow, as is the case with actual levees.

\subsection{Experiment apparatuses}

Upon installing a movable imaging and measuring platform within the experimental channel, five GoPro devices, one digital camera, and three VR cameras capable of rotating 360 degrees were placed in areas to the front and both sides of the point of levee failure, and the numerous cameras were used to film the entire experimental process including close-up shots of failure sections and the progression of scour that occurred along the levee slope. Manifestations of failure along the levee crown were filmed using a drone. 


\subsection{Creating a levee model}

Based on the soil classification system, uniform well-graded sand (SW), in which $50 \%$ is retained on or above a No. 200 sieve was used. By using this type of soil, which is vulnerable to crack, the performance of the bio-polymer mixed with the most vulnerable of materials becomes more apparent, and the formation of overflow breach cross-sections is induced. Since the sand used in the experiment changes each time, three times of particle size distribution tests was conducted to verify the consistency of each test in Figure 3.

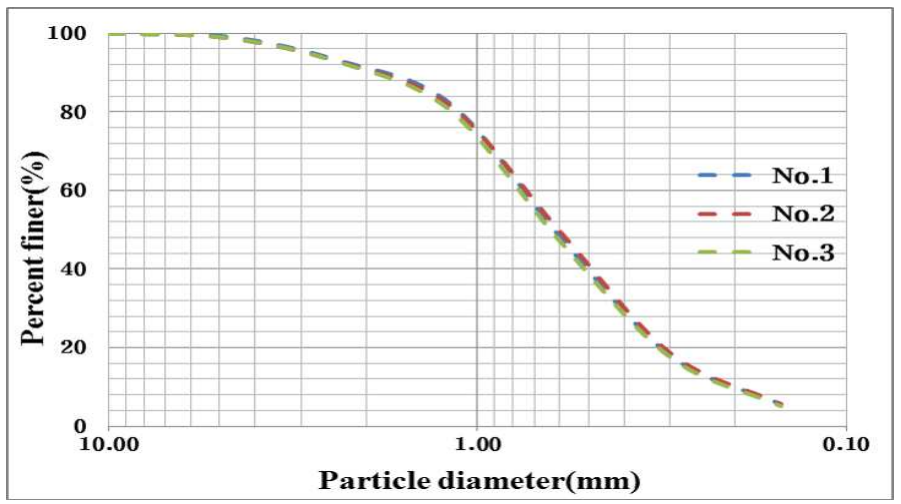

\section{Fig. 3. Grain size distribution}

Using an excavator $\left(0.2 \mathrm{~m}^{3}\right)$, the sand was then dropped from a height of $3 \mathrm{~m}$ and was used to build the base of the levee. Next, the levee was built by repeatedly placing waterpacked $20 \mathrm{~cm}$ layers on top of each other. The application of a new material was based on a provided recipe from the joint research institute KAIST, a powder type bio-polymer was mixed with water. The bio-polymer solution was then mixed with soil, and this mixture was spread across the levee surface to a thickness that was appropriate for experiment conditions in Figure 4. Thereafter, the experiments were undertaken following a period of $3 \sim 5$ days of curing, a time at which overflow failure experiments would become possible.
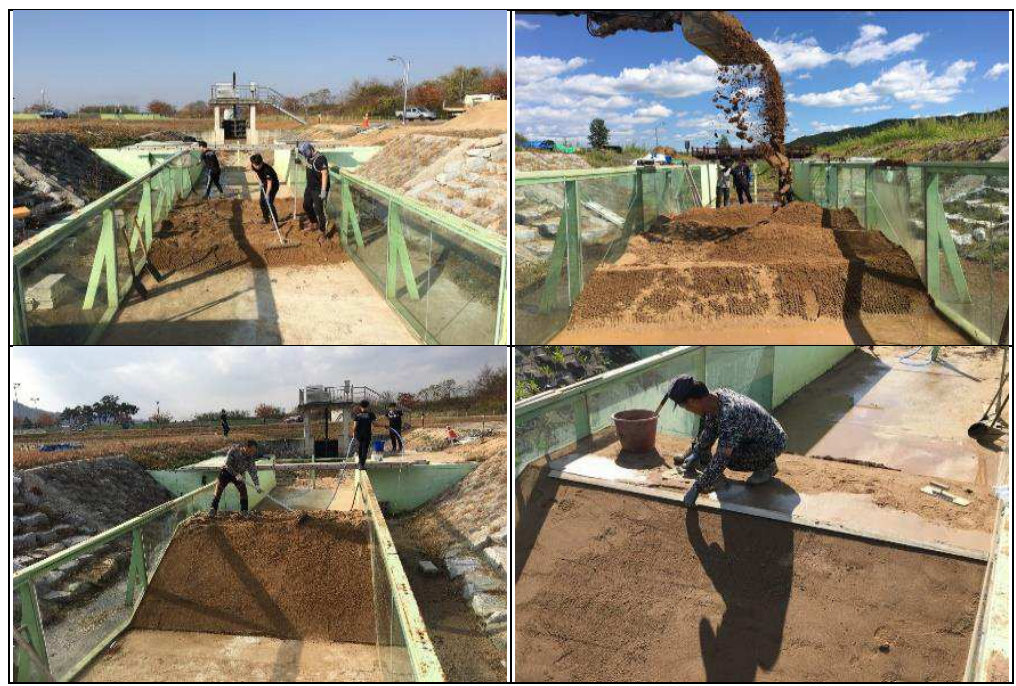

Fig. 4. Building a levee model 


\subsection{Experimental discharge control}

This experiments were not carried out by inducing levee failure through an inflow from the upstream area of the A3 channel in which the flow would travel along existing pathways, but rather were performed by first creating a flow volume of $3 \mathrm{~m}^{3} / \mathrm{s}$ along the A1 channel, a channel unaffected by the experiment, to gradually raise the water levels of the downstream outflow pond and develop a back flow into the downstream area of the A3 channel, which would subsequently produce an overflow.

\section{Results}

Changes in the progression of levee failure due to overflow were classified into 4 steps at intervals of 30 seconds arbitrarily. This figure is purely aimed at visualizing the breaching mechanism due to overflow, and this is to confirm the installation area of the reinforcement through review of the breaching vulnerability.

The first step presented the appearance of levee failure 30 seconds after overflow began, in which gradual erosion was observed across the levee crown and slope surface towards the land side area, from the point at which the overflow occurred. This is considered to be the step in which an initial flow was created on the levee slope, which led to erosion and the development of the main flow waterway.

The second step presented the appearance of levee failure 60 seconds after overflow began, continued flow and development of flow velocities along the levee slope resulted in erosion along the direction of the flow of water, which presented the development of gully erosions forming a small valley.

The third step presented the appearance of levee failure 90 seconds after overflow began, a stairwell shaped overflow flow was developed due to erosion across the levee crown. As the width of the breach expanded under continued flow, the overflow volume increased and

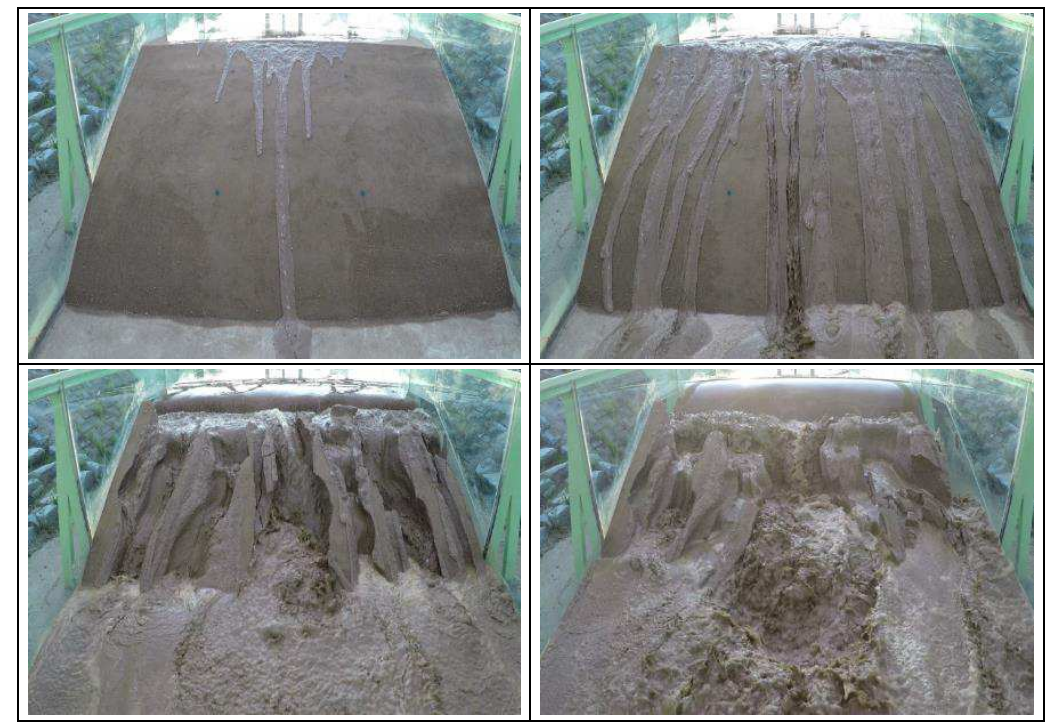

Fig. 5. Breaching shape under time since onset of overflow

accelerated levee erosions and vertical erosions were formed on the overflow cross-section.

The fourth step presented the appearance of levee failure 120 seconds after overflow began, the complete failure of the levee crown and the rapid increase of overflow volumes resulted, 
and caused the breach width to reach its maximum levels due to the strong tractive forces. Figure 5 shows breaching shape under time since onset of overflow.

Upon editing and analyzing the video of the experiment collected from the imaging and measuring system, the size of the failures according to the lapse of time were reviewed. The method of analysis first involved capturing and adjusting the filmed levee slopes in temporal units, after which a digitizing process was undertaken to designate the range of the failed area. Subsequently, graphics software was used to perform a pixel-based analysis of the area concerned, in which the size of the failure was calculated in 30-second intervals, and surface loss rates were calculated thereafter.

Through a pixel-based analysis performed to analyze levee surface loss rates for the levee that applied new material (Case 2, 4), surface loss was between $1 \sim 2 \% 30$ seconds after the overflow began, $2 \sim 42 \%$ after 60 seconds, $27 \sim 63 \%$ after 90 seconds, $54 \sim 69 \%$ after 120 seconds, $67 \sim 78 \%$ after 150 seconds, $72 \sim 81 \%$ after 180 seconds, $74 \sim 84 \%$ after 210 seconds, $78 \sim 87 \%$ after 240 seconds, and $88 \sim 90 \%$ after 270 seconds. The results indicated widely varying loss rates at the 60 second mark and 90 second mark. This was considered to have been due to the effect that cracks developed during the curing process had on the initial failure rates. What was interesting to note was that the margins of the loss rates were reduced to within $10 \%$ with the passage of time.

Compared to the earthen levee (Case 1,3), the levee that applied new material was found to take $2.25 \mathrm{x}$ longer to reach total levee failure. Through the levee surface loss rate analysis according to the passage of time performed through the pixel based analysis, the initial breach velocity of the earthen levee was found to be $1.43 \mathrm{x}$ faster than the levee that applied new material, and the failure was also found to accelerate more rapidly with the passing of time in Figure 6.

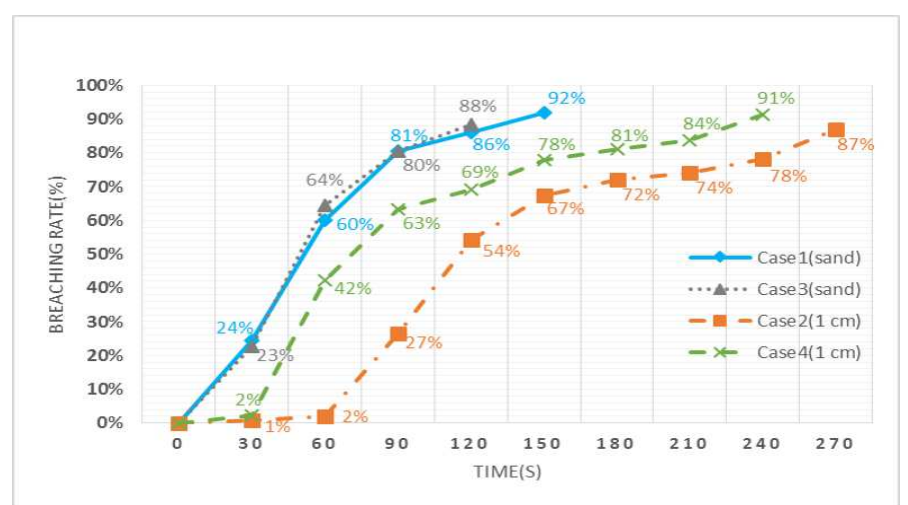

Fig. 6. Breaching rate

ACKNOWLEDGMENT: This research described in this paper was financially supported by a grant (17AWMP-B114119-02) from Advanced Water Management Research Program funded by Ministry of Land, Infrastructure and Transport of Korean government.

\section{References}

1. G. J. Hanson, K. R. Cook, S. L. Hunt, ASAEs, 48, 5 (2005)

2. Y. Kurakami, Y. Nihei, K. Yada, T. Yamazaki, S. Yamaguchi, S. Kawabe, Y. Kikuchi, F. Tatsuoka, J. JSCE, 69, 4 (2013) 
3. D. Tobita, T. Kakinuma, H. Yokoyama, A. Takeda, J. JSCE, 2, 1 (2014)

4. J. A. Feliciano C, J. Imran, M. Hanif C, J. Hydraulic Engineering, 141, 4 (2015)

5. J. M. Kim, M. C. Park, I. J. Moon, Y. H. Jin, J. KGSS, 16, 1 (2017) 